\title{
FERRAMENTAS DE GESTÃO ESTRATÉGICA PARA OTIMIZAÇÃO DE DESEMPENHO
}

Valmir Emil Hoffmann ${ }^{1}$

Eduardo Cury Damico ${ }^{1}$

Cleidson Nogueira Dias ${ }^{2}$

\footnotetext{
${ }^{1}$ Universidade de Brasília

${ }^{2}$ Empresa Brasileira de Pesquisa Agropecuária (Embrapa) e Universidade de Brasília (UnB)
} 


\title{
FERRAMENTAS DE GESTÃO ESTRATÉGICA PARA OTIMIZAÇÃO DE DESEMPENHO
}

\begin{abstract}
Resumo: O objetivo geral deste trabalho é determinar a relação entre o desempenho de Empresas Juniores brasilienses com as ferramentas de gestão utilizadas. No que tange os aspectos metodológicos a presente pesquisa é de caráter descritivo e utilizou o método Análise Qualitativa Comparativa (QCA), valendo-se da lógica Crisp-set, para análise de dados primários coletados a partir da aplicação de questionários em empresas juniores no Distrito Federal. Os resultados destacam as análises acerca das ferramentas de gestão estratégica que influenciam o desempenho das variáveis construídas. As ferramentas cuja presença levaram ao alto desempenho foram Análise de Stakeholders individualmente, Análise de Cenários somada à Análise de Stakeholders, o CRM, o Balanced Scorecard somado Análise de Cenários e CRM com Análise de Cenários desencadeiam alto desempenho. Adicionalmente, são apresentados direcionamentos para realização de estudos similares em outros Estados e até outros países que contem com a presença do Movimento Empresa Júnior.
\end{abstract}

Palavras-chave: Desempenho. Ferramentas de gestão. Estratégia. Pequenas Empresas.

\section{$1 \quad$ Introdução}

O trabalho de Rumelt, Schendel e Teece (1994) traz à tona o debate sobre os problemas das organizações. Uma das questões levantadas analisa o porquê das organizações serem diferentes, competirem em diversos aspectos e quais fatores sustentam a heterogeneidade e que consequentemente as leva a terem desempenhos distintos.

Relatos de Hunger e Wheelen (2002) descrevem o O trabalho de Rumelt, Schendel e Teece (1994) traz à tona o debate sobre os problemas das organizações. Uma das questões levantadas analisa o porquê das organizações serem diferentes, competirem em diversos aspectos e quais fatores sustentam a heterogeneidade e que consequentemente as leva a terem desempenhos distintos.

Relatos de Hunger e Wheelen (2002) descrevem o impacto das ferramentas de gestão sobre desempenho organizacional. Desempenho é considerado o conjunto de resultados que uma organização apresenta em determinado período de tempo, de acordo com Fernandes, Fleury e Mills (2006). Assim, as feramentas de gestão auxiliam executivos a atingirem seus objetivos, sejam eles aumentar receitas, reduzir custos, inovar, melhorar a qualidade ou se planejar para o futuro (RIGBY, 2009).

O debate acerca do desempenho organizacional pode ser replicado à realidade de Empresas Juniores. Apesar de possuírem diversas características base em comum, observa-se que seus desempenhos são discrepantes. O Relatório do Censo de 2015 apresenta dados sobre o desempenho de cada federação do Movimento Empresa Júnior (MEJ) brasileiro.

De acordo com os censos, entre 2013 e 2014, o Movimento Empresa Junior (MEJ) no Brasil apresentou um crescimento surpreendente. Registrou-se mais de $60 \%$ de aumento no número de empresas, de 283 para 427, e de membros respondentes, de 3188 para 5150 . O faturamento foi $\mathrm{R} \$ 13.067 .638$ no ano de 2014, valor superior em $21,6 \%$ em relação ao ano anterior, de R $\$ 10.749 .717$. Em 2014, cada Empresa Júnior foi responsável pela realização de 5,9 projetos por ano, desempenho pouco superior ao do ano anterior de 5,2 projetos por ano (BRASIL JÚNIOR, 2014). Com isso, verifica-se que os serviços prestados têm apresentado valorização crescente no mercado brasileiro.
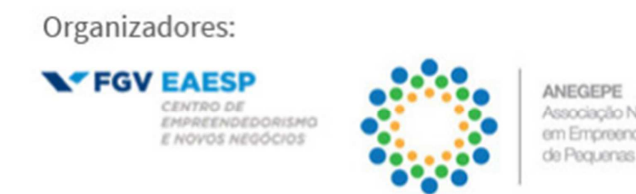

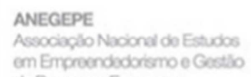
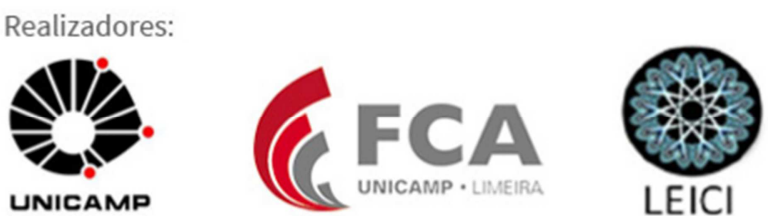
O relatório da Brasil Júnior (BJ) de 2014, demonstra pontos que impactam diretamente no desempenho de uma empresa júnior. Primeiramente, foi demonstrado que $45,69 \%$ das EJs utilizam algum modelo de gestão específico, 34,91\% tem conhecimento de modelos de gestão, porém não utiliza nenhum e 19,40\% desconhece modelos de gestão específicos. A respeito da orientação para projetos foi levantado que, 56,03\% das EJs recorrem a professores não remunerados, $1,51 \%$ utilizam de professores remunerados, $5,39 \%$ têm projetos sem orientação, $6,25 \%$ são orientados por ex-membros da EJ, 13,79\% utilizam orientadores externos, 6,25\% utilizam pós-graduandos e 10,78\% utilizam outras formas de orientação. Sobre a coleta da satisfação do cliente, percebeu-se que $68,53 \%$ das EJs coletam feedbacks acerca da satisfação de seus clientes, enquanto $31,47 \%$ não realizam esta atividade. Por fim, foram levantados os critérios nos quais as EJs apresentam maior dificuldade, e estes foram: Clientes, Estratégias e Resultados (BRASIL JÚNIOR, 2014).

Nesse sentido, o objetivo geral deste trabalho é determinar a relação entre o desempenho de Empresas Juniores (EJs) brasilienses com as ferramentas de gestão utilizadas e stakeholders envolvidos. Para o alcance dessa finalidade, os objetivos específicos do presente trabalho fundamentam-se em: i) identificar as ferramentas adotadas pelas Empresas Juniores; ii) apurar os resultados obtidos nos últimos três anos das EJs da Concentro (Federação de Empresas Juniores do Distrito Federal); e iii) determinar quais ferramentas e quais stakeholders levam as Empresas Juniores a desenvolverem alto desempenho organizacional.

Assim, o presente trabalho busca as influencias no desempenho com as ferramentas de gestão na realidade de Empresas Juniores do cenário brasiliense. Então, foi realizado o levantamento de informações referentes ao desempenho de Empresas Juniores no mercado brasiliense, quais ferramentas de gestão utilizam, quais os stakeholders são priorizados e quais práticas são referência para uma gestão de qualidade nessa realidade.

\section{Referencial Teórico}

O referencial teórico do trabalho será centrado nas ferramentas de gestão e stakeholders abordados na pesquisa a ser realizada, além de fornecer um embasamento teórico no que diz respeito à concepção, forma de atuação e importância das Empresas Juniores. Levando em conta os trabalhos de Vendruscolo, Hoffmann e Freitas (2012), e Nascimento, Hoffmann e Farias (2014), foram elencadas as seguintes ferramentas: Orçamento, Planejamento Estratégico e Matriz SWOT, Balanced Scorecard (BSC), Sistemas de Informação Estratégica (Softwares), Benchmarking e Análise de Stakeholders. Foram discutidos e analisados os impactos destas sobre desempenho organizacional das organizações do ramo particular de saúde e unidade de assistência de saúde, ambas no Distrito Federal.

O orçamento pode ser definido como uma expressão quantitativa, formal e detalhada de um plano de ação que visa atingir objetivos estratégicos escolhidos para um determinado período, assim, demonstrações financeiras elaboradas podem ser, referentes à períodos passados ou futuros, como demonstração de resultados, fluxo de caixa e balanço patrimonial orçados (HORNGREN, 1997; PASSARELLI, BOMFIM, 2004). Baseando-se nesse conceito de orçamento, Passarelli e Bomfim (2004) ainda apresentam uma definição mais simplista da ferramenta, a considerando como a simples fixação de limites de despesas para a administração, objetivando a promoção da utilização dos recursos de forma mais produtiva e lucrativa.
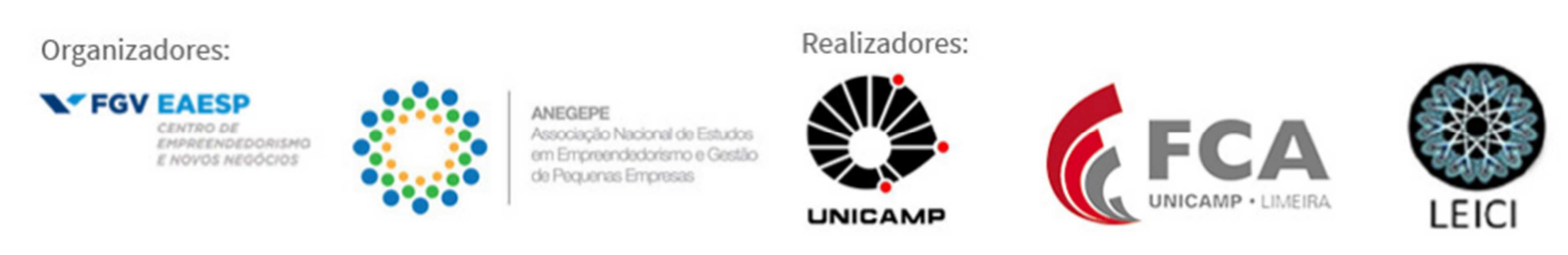
Lunkes (2003) ressalta a percepção de variabilidade do orçamento de acordo com as necessidades de uma organização, compreendendo a elaboração de planos detalhados e objetivos de lucro, previsão de despesas dentro da estrutura dos planos e políticas existentes, além da fixação de padrões definidos de atuação para indivíduos com responsabilidade de supervisão. Sendo assim, o orçamento aproxima as projeções estabelecidas à realidade alcançada pela organização, sem gerar novos riscos (FREZATTI, 2007). Ferreira et al. (2016) sugerem que a utilização dessa ferramenta de gestão, somada ao planejamento facilitou a gestão pública do Estado de Minas Gerais, após o choque de gestão consequente à uma crise.

Tanto Costa (1999) quanto Rigby (2009) apresentam em suas obras o benchmarking como uma ferramenta de gestão que busca a melhoria de processos, práticas e resultados, a partir da identificação de condutas mais eficazes em competidores, empresas-modelo ou em diferentes áreas da própria organização. A partir da comparação de desempenhos realizada pelos gestores, torna-se possível a incorporação das melhores práticas às operações através da inovação, buscando alcançar o progresso idealizado (RIGBY, 2009).

A necessidade dessa ferramenta é notável, pois pode resultar no aumento da competitividade empresarial, da excepcionalidade de desempenho, qualidade e satisfação de clientes a partir do levantamento de práticas que resultam em uma performance superior e da incorporação dessas às suas operações, através da inovação (CARLINI, VITAL, 2004; RIGBY, 2009). Silva e Fonseca (2009) apresentam o benchmarking como agente da mudança da Marinha brasileira, alterando a forma com que a organização opera sua administração pública buscando a redução de custos e de aumento da qualidade dos serviços prestados aos cidadãos.

No que tange o Planejamento Estratégico e Análise SWOT, o Planejamento Estratégico consiste em um instrumento de gestão cuja base é um método estruturado de tomada de decisões, visando a situação futura desejada pela organização, explicitando as ações e recursos necessários para o alcance dos objetivos estratégicos delimitados (DEITSCHI, NASCIMENTO, 2008; RIGBY, 2009). Ackoff (1980) complementa com a percepção de que a estruturação do planejamento empresarial objetiva tanto prevenir ações incorretas, quanto reduzir a frequência dos fracassos da empresa.

Deitschi e Nascimento (2008) enfatizam a visão sistêmica do Planejamento Estratégico através do conceito que envolve a noção de hierarquia de decisões, em que cada passo, no sentido descendente, corresponde à implementação de um objetivo estabelecido no plano imediatamente anterior. Dessa forma, pode-se inferir que as ações operacionais mais relevantes de uma organização são um reflexo de decisões tomadas no passado.

Rezende (2003) enfatiza a importância da utilização de ferramentas de gestão como a Análise SWOT para a elaboração de um planejamento estratégico. A última representa uma avaliação global das forças, fraquezas, ameaças e oportunidades de uma organização, sendo estas divididas em fatores internos controláveis e fatores externos incontroláveis (Mintzberg, Lampel, Ahlstrand, 2000).

Silva e Assis (2016) salientam o papel fundamental do Planejamento Estratégico na reestruturação da gestão estratégica da Empresa Brasileira de Serviços Hospitalares, permitindo o aprimoramento de seus processos e consequentemente do serviço prestado pela instituição, e Presrlak (2016) apresenta o êxito da aplicação da análise de SWOT a uma microempresa do setor de serviços contábeis, no qual foi possível à organização adquirir uma visão mais clara do

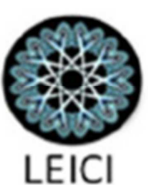


ambiente global em que está inserida, embasando direcionamentos para o plano de marketing posteriormente estruturado.

Além disso, Kaplan e Norton (1997) idealizaram o Balanced Scorecard (BSC), uma ferramenta que visa a integração de estratégias ao comunicar-se com processos e sistemas de uma determinada organização, além de oferecer retroalimentação para toda a estrutura. A importância do BSC está associada às ações estratégicas voltadas para a missão organizacional e não somente a ativos intangíveis. Rigby (2009) complementa ao afirmar que o BSC determina o desempenho organizacional com base na visão dos gestores e o mede a partir do alcance ou não dos objetivos esperados, traduzindo assim a missão e visão da empresa em um conjunto de métricas de desempenho claro e mensurável.

Davis e Albright (2004) averiguaram a capacidade do BSC de aprimorar a performance financeira de uma organização. Foi analisado que, após a implementação, o desempenho é consideravelmente superior ao de uma organização em ambiente similar cuja implementação não foi realizada. Além disso, Afonso at el. (2015) apresentam o sucesso da implementação do BSC por quinze Tribunais de Contas Estaduais, levando à evolução da gestão governamental brasileira, uma vez que a partir do emprego dessa ferramenta, os gestores transmitiram a seus subordinados os valores organizacionais e metas a serem atingidas, determinando assim um rumo e, consequentemente, os resultados dos órgãos.

Sobre Sistemas de Informação Estratégica (Softwares), a importância da utilização de Sistemas de Informação para gestão é levantada na obra de Farias (2011), que afirma que os softwares podem agir tanto auxiliando no processo de tomada de decisão e estratégia organizacional como no contexto gerencial e operacional da entidade. Beal (2004), Cruz (2003) e Calazans (2006) apresentam em suas obras o viés mais estratégico da ferramenta ao destacarem que seu objetivo de traduzir dados em informações, permitindo a realização de análises correlatas, seja do ambiente interno ou externo, no intuito de auxiliar no gerenciamento de recursos e na tomada de decisão estratégica. Assim, as adaptações alinham-se às mudanças exigidas pelas transformações do ambiente no qual a organização está inserida, solucionando conflitos e mudanças intrínsecas a esse.

Maruyama e Rodrigues (2016) apresentam a aplicação de softwares por uma organização que lida com processamento eletrônico de cheques, que, com sucesso, gerencia o fluxo dinâmico de informações com que lida diariamente, estruturando assim uma gestão de conhecimento e de informações. Isso levou ao aprimoramento da tomada de decisão e estruturação de uma cultura voltada para gestão de dados.

Para Morgan e Hunt (1994, p.22), a Gestão do Marketing de Relacionamento (CRM) consiste no "conjunto de atividades de marketing direcionadas ao estabelecimento, desenvolvimento e prosseguimento de trocas relacionais bem-sucedidas". A prática do CRM permite que empresas coletem uma grande quantidade de dados, que após análise, levam a equipe a um maior entendimento sobre os grupos de clientes e a elaboração estratégias, como a definição de clientes-alvo e estruturação de esforços para conquista-los, oferendo valor por meio de ofertas customizadas e desenvolvimento de relacionamentos duradouros (RIGBY, 2009; PAYNE, 2006). Segundo Rigby (2009), o instrumento ainda fornece insumos sobre comportamentos e necessidades dos consumidores, para responder mais rapidamente às mudanças nos desejos dos mesmos e desenvolver produtos mais alinhados para o segmento em questão (RIGBY, 2009).
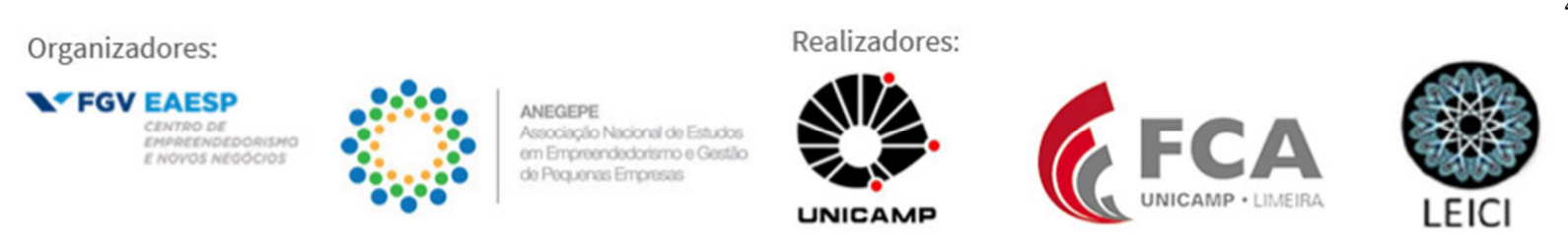
O estudo de Silva e Silva (2008) ressalta a importância de estratégias de CRM para o setor de hotelaria, no intuito de captar e utilizar informações visando aprimorar a prestação de serviços com a superação constante de expectativas dos clientes. Da mesma forma, Medeiros, Cas e Medeiros (2016) exaltam o sucesso da utilização da ferramenta reativando clientes antigos em uma concessionária de veículos comerciais em Santa Maria - RS.

Já a ferramenta de Análise de Cenários, na concepção de Porter (1989), os cenários representam uma visão internamente consistente do futuro que poderá se efetivar. A finalidade da análise destes, consiste em possibilitar a compreensão de diversas ameaças que a organização poderá enfrentar em dado horizonte e conduz à estruturação uma visão de longo prazo com planos de contenção, complementando o planejamento de longo prazo, trazendo uma visão mais clara do futuro e incorporando efeitos da globalização e de mudanças repentinas de mercado, rupturas de negócio e alterações no gerenciamento em questões estratégicas, consequentemente aprimoramento o processo decisório da organização (RIGBY, 2009).

Furlan (2014) analisa a aplicação da análise de cenários em cooperativas agroindustriais do Paraná, traduzindo-se o esforço das organizações em compreender e antever o futuro, considerando as tendências para uma tomada de decisão, que impacta em milhares de pessoas ligadas ao cooperativismo.

Por fim, na Análise de Stakeholders, destaca-se que a definição de Stakeholders pode ser atribuída a grupos ou pessoas que reivindicam legitimamente pertencimento, direitos ou interesses em procedimentos ou aspectos substantivos das atividades corporativas, sejam estas do passado, presente ou futuro (CLARKSON, 1995; DONALDSON, PRESTON, 1995). Porém a definição mais reconhecida na literatura é a de Freeman (1985, p.46), na qual stakeholders podem ser identificados sobre duas óticas distintas, (i) uma mais abrangente, qualquer grupo ou indivíduo, identificável, que possa afetar a consecução dos objetivos de uma organização ou que, inversamente, é afetado pela consecução dos objetivos de uma organização; (ii) outra mais restrita, como qualquer grupo ou indivíduo, no qual a organização é dependente para a sua sobrevivência contínua.

A identificação dos principais stakeholders de uma organização permite o levantamento e gerenciamento de seus interesses, o que possibilita a elaboração de respostas mais alinhadas às demandadas internas e externas, e assim, gera mais valor e permite construir relacionamentos mais estreitos (STARIK, 1995; BANSAL, 2005; GRUNDY, 2005).

Ortega, Boaventura e Mascena (2016) discutem a hipótese do atendimento ao stakeholder franqueado estar diretamente ligado ao desempenho financeiro da franquia. Tal hipótese foi refutada e ainda foi analisada uma relação negativa entre marca e desempenho financeiro. Segundo os autores, tal resultado propõe a criação de valor no relacionamento com diversos grupos de stakeholders simultaneamente e não apenas a priorização do relacionamento com o stakeholder mais relevante.

\section{Métodos e Técnicas de Pesquisa}

Nesta etapa do trabalho são detalhados o tipo e a descrição geral da pesquisa; as organizações estudadas; população e amostra utilizada; os instrumentos de pesquisa; e os procedimentos de coleta e análise de dados.

\subsection{Tipo e descrição geral da pesquisa e Caracterização do Objeto}

Organizadores:
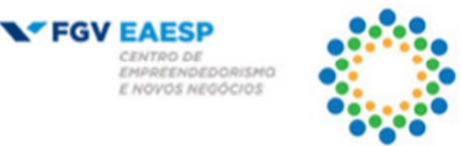

ANEGEPE Associaplo Nooind do Estwosos de Expquenos Enposeses

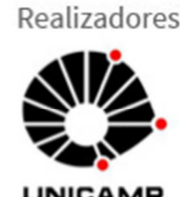

UNICAMP
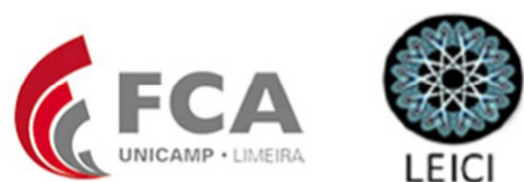
A pesquisa tem caráter descritivo a partir de dados primários coletados com a aplicação de questionários. Foi utilizada uma abordagem mista, considerando aspectos qualitativos e quantitativos.

As Empresas Juniores (EJs) são associações civis sem fins lucrativos, constituídas e geridas por estudantes do curso superior, que têm como objetivo proporcionar-lhes a aplicação e aprimoramento dos conhecimentos teóricos obtidos ao longo de sua formação acadêmica (FANAYA JUNIOR et al., 2010; RODRIGUES et al., 2010; BRASIL JÚNIOR, 2011), em um ambiente empresarial, lidando com clientes e gerenciamento tanto de recursos quanto de stakeholders.

Segundo a Brasil Júnior (2010) O Movimento Empresa Junior (MEJ) consiste no conjunto de Empresas Juniores que têm o intuito de fomentar comportamentos empreendedores desde a graduação. As Empresas Juniores surgiram na França, em 1967, através da iniciativa de uma estudante que fomentou e introduziu no mercado um projeto que visava colocar à disposição de empresas seniores os seus trabalhos administrativos a preços abaixo do mercado (MORETTO et al, 2004). A Brasil Júnior - Confederação Brasileira de Empresas Juniores - foi criada em 2003, e possui a função de regulamentar e auxiliar as Empresas Juniores ao redor do Brasil, possibilitando alcançarem o desenvolvimento desejado (Brasil Júnior, 2010).

No Relatório Censo Identidade (Brasil Júnior, 2014), é possível encontrar informações a respeito do Conceito Nacional de Empresas Juniores (CNEJ). Esse documento foi criado e desenvolvido pela Brasil Júnior, determinando os fatores a serem respeitados e seguidos pelas organizações, para que esta possa ser reconhecida como uma Empresa Júnior. No artigo $3^{\circ}$ do CNEJ, é apresentado uma característica que determinante para a forma de atuação do Movimento Empresa Júnior: "Desenvolver profissionalmente as pessoas que compõem o quadro social por meio da vivencia empresarial, realizando projetos e serviços na área de atuação do(s) cursos de graduação ao(s) qual(is) a Empresa Júnior for vinculada." (BRASIL JÚNIOR, 2010).

Essa característica é ressaltada por Moretto et al. (2004), ao afirmar que o MEJ tem papel importante no desenvolvimento e qualificação dos empresários juniores no Brasil visto que, durante sua permanência no Movimento, são realizados intercâmbios, provenientes de benchmarkings constantes de informações entre as EJs, uma vez que existem diversas estruturas do MEJ em esfera estadual e nacional.

Assim, as Empresas Juniores, que por meio de projetos de consultoria (MATOS, 1997), desenvolvem seus membros em uma realidade empresarial, utilizam-se de ferramentas de gestão para se posicionarem competitivamente frente a outras Empresas Juniores e até com empresas seniores.

\subsection{População e amostra}

O estudo baseia-se no censo das EJs da Concentro (Federação das Empresas Juniores do Distrito Federal). Ou seja, todas as Empresas Juniores do Distrito Federal, independente da Universidade com quais estas estão vinculadas.

Foram determinadas métricas de desempenho que restringem os participantes do estudo, uma vez que para serem levantadas as relações de suficiência e necessidade, é necessária uma análise histórica dos últimos 3 anos (2014-2016) que permite a análise da curva de desempenho. As variáveis dependentes para a análise dos resultados organizacionais de cada uma das Empresas Juniores são: (i) faturamento e (ii) número de membros efetivos e tempo que estes permanecem nas EJs. O faturamento está diretamente ligado ao serviço prestado e ao ticket

Organizadores:

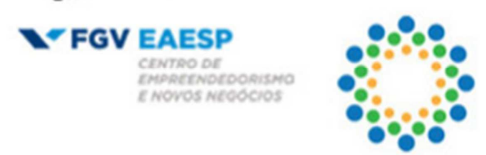

ANEGEPE Associoplo Nowond de Estudas

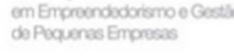
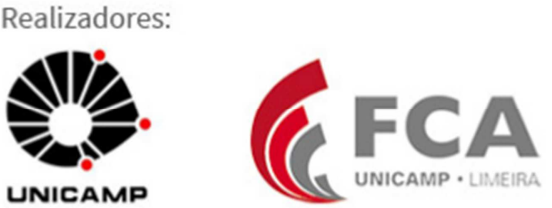

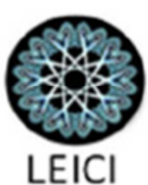


médio (preço médio de projetos), correspondendo aos resultados monetários para os serviços prestados. O número de membros e tempo de permanência desses, diz respeito à adesão dos alunos de graduação para participar do MEJ (Movimento Empresa Júnior), que é um dos principais stakeholders destas organizações.

\subsection{Instrumento de pesquisa e Procedimentos de coleta e tratamento de dados}

$\mathrm{O}$ instrumento de pesquisa utilizado para a coleta de dados foi um questionário elaborado na plataforma eletrônica de construção de formulários GoogleForms. O formulário encaminhado foi dividido em quatro sessões: (i) Categorização da EJ, (ii) Categorização do Respondente, (iii) Ferramentas de Gestão e (iv) Desempenho Organizacional.

Antes da aplicação dos questionários, foi realizado um pré-teste seguindo os princípios apontados por Vergara (2007). Nessa etapa, foram coletadas as percepções de respondentes externos ao estudo. A amostra era de dois membros ligados ao Movimento Empresa Júnior escolhidos por conveniência. Foi firmado um acordo confidencialidade para evitar influência negativa nas respostas. Assim como o estudo, a aplicação se deu no meio eletrônico e permitiu a adaptação para que este chegasse ao formato ideal. Suas sugestões foram incorporadas ao texto final do questionário.

A coleta de informações se deu durante o mês março de 2017, a partir do encaminhamento dos questionários para o e-mail institucional de cada uma das Empresas Juniores federadas pela Concentro (Federação das Empresas Juniores do Distrito Federal), em que se apresentava a proposta do estudo e os benefícios do mesmo para o MEJ brasiliense.

Apesar de a proposta inicial ser de realização de um estudo com todas as empresas elencadas no censo das Empresas Juniores do Distrito Federal participantes da Federação das Empresas Juniores do Distrito Federal (Concentro), foram coletadas 28 respostas das 36 Empresas Juniores participantes da federação.

Foi necessário filtrar as 28 Empresas Juniores respondentes, em função da ausência de algum dado central dos resultados de faturamento ou membros, cuja ausência iria prejudicar a realização de análises. Assim, o estudo contou 14 Empresas Juniores, cujos nomes foram preservados com o intuito de não impactar a imagem organizacional frente ao mercado brasiliense. Para isso cada caso foi descrito como EJ1, EJ2 (...), EJ14. Além disso, percebeu-se de imediato a ausência de casos na ferramenta $5 \mathrm{~S}$ e a presença de apenas uma ocorrência da ferramenta curva $\mathrm{ABC}$, o que inviabilizaria a análise de sua influência. Em decorrência destes fatos, ambas as ferramentas foram retiradas da análise de dados.

Os dados foram tabulados em uma planilha do Excel, onde as linhas continham os dados de cada EJ, as colunas os dados de ausência e presença das ferramentas. As últimas 3 colunas contêm informações sobre o desempenho das Empresas Juniores, com base nas métricas elaboradas.

Já o tratamento dos dados coletados pela pesquisa se deu a partir de estatística descritiva. Para as ferramentas de gestão, foi definido que além da afirmação da utilização da ferramenta, que necessariamente tivesse grau de importância 3 ou mais para determinar o alto grau de influência de tal ferramenta no desempenho organizacional de acordo com a tabela abaixo. Determinou-se o valor 1 como indicativo de presença do alto grau de influência da ferramenta e o valor 0 como ausência deste alto grau de influência da ferramenta levantada (Quadro 1).

Quadro 1 - Ferramentas de Gestão e seus valores

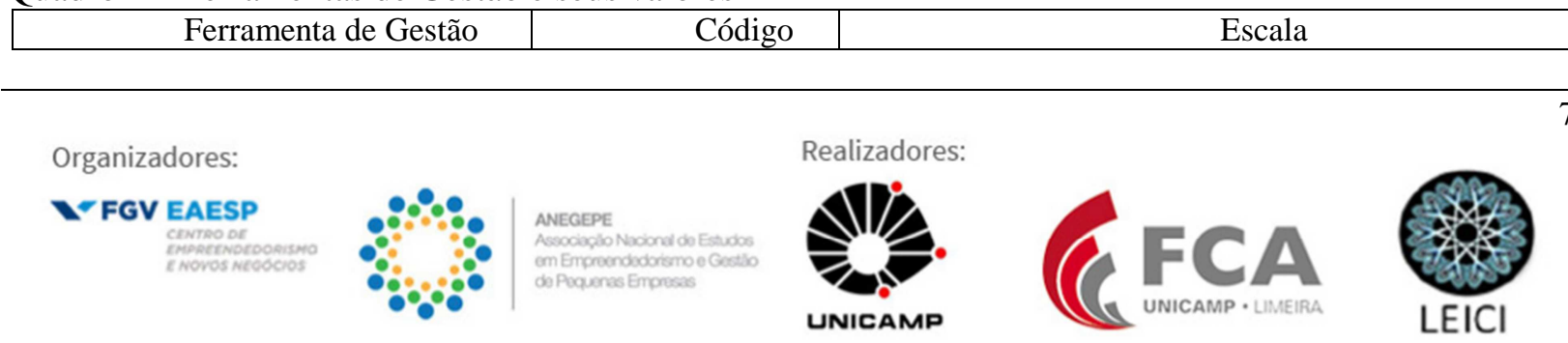




\begin{tabular}{|l|l|l|}
\hline Orçamento & ORC & $\begin{array}{l}\text { 1=presença de alto grau de influência; 0=ausência } \\
\text { de alto grau de influência }\end{array}$ \\
\hline Benchmarking & BENCH & $\begin{array}{l}\text { 1=presença de alto grau de influência; 0=ausência } \\
\text { de alto grau de influência }\end{array}$ \\
\hline $\begin{array}{l}\text { Planejamento Estratégico e Análise } \\
\text { de SWOT }\end{array}$ & PEeSWOT & $\begin{array}{l}\text { 1=presença de alto grau de influência; 0=ausência } \\
\text { de alto grau de influência }\end{array}$ \\
\hline Balanced Scorecard & BSC & $\begin{array}{l}\text { 1=presença de alto grau de influência; 0=ausência } \\
\text { de alto grau de influência }\end{array}$ \\
\hline Softwares & SOFT & $\begin{array}{l}\text { 1=presença de alto grau de influência; 0=ausência } \\
\text { de alto grau de influência }\end{array}$ \\
\hline $\begin{array}{l}\text { Marketing de Relacionamento } \\
\text { (CRM) }\end{array}$ & CRM & $\begin{array}{l}\text { 1=presença de alto grau de influência; 0=ausência } \\
\text { de alto grau de influência }\end{array}$ \\
\hline Análise de Cenários & AC & $\begin{array}{l}\text { 1=presença de alto grau de influência; 0=ausência } \\
\text { de alto grau de influência }\end{array}$ \\
\hline Análise de Stakeholders & AS & $\begin{array}{l}\text { 1=presença de alto grau de influência; 0=ausência } \\
\text { de alto grau de influência }\end{array}$ \\
\hline
\end{tabular}

Fonte: Elaboração própria com base em Dias (2015).

Acerca dos resultados organizacionais, visando uma análise mais objetiva, as variáveis de desempenho foram compiladas em faturamento por membro e uma relação entre número de membros e tempo em que permanecem, permitindo assim uma análise mais condizente com cada realidade organizacional, visto a divergência de contextos mercadológicos e históricos de cada Empresa Júnior. Estes foram tratados tendo como base a mediana, assim, valores acima da mediana, configuraram a presença de um alto desempeno, e valores no Quadro 2 configuraram a ausência deste alto desempenho.

Quadro 2 - Critérios de desempenho das EJs e seus valores

\begin{tabular}{|l|l|l|}
\hline \multicolumn{1}{|c|}{ Métrica Utilizada } & \multicolumn{1}{|c|}{ Mediana } & \multicolumn{1}{c|}{ Escala } \\
\hline Faturamento por Membro & R\$641,75 por membro & $\begin{array}{l}1=\text { valor acima ou igual mediana; } \\
0=\text { valor até a mediana }\end{array}$ \\
\hline $\begin{array}{l}\text { Número de Membros e Tempo de } \\
\text { Permanência destes }\end{array}$ & $\begin{array}{l}44 \text { membros e um tempo } \\
\text { médio de permanência entre } \\
13 \text { e } 18 \text { meses }\end{array}$ & $\begin{array}{l}1=\text { valor acima ou igual a mediana em } \\
\text { ambos os critérios; 0 valor abaixo da } \\
\text { mediana em algum dos critérios }\end{array}$ \\
\hline
\end{tabular}

Fonte: Elaborado própria com base em Dias (2015)

Para a análise de dados, foi utilizada a técnica QCA, Análise Comparativa Qualitativa (QCA- Quantitative Comparative Analysis), uma abordagem analítica, que considera detalhadamente cada um dos casos abordados com comparações entre seus cruzamentos (RIHOUX, ÁLAMOS-CONCHA, BOL, MARX \& REZSÖHAZY, 2013).

Segundo Ragin (1987), o idealizador do método, o QCA conecta as análises qualitativas e quantitativas. A ferramenta é capaz de pontuar padrões decisivos para os casos levantados. Possibilitando o estudo de condições que são insuficientes, porém, partes necessárias das receitas causais. Ou seja, com base de diferentes combinações de condições causais é possível averiguar a geração de um mesmo resultado.

O método, é a ferramenta mais condizente para a realização de uma pesquisa cuja amostra é pequena ou intermediária, permitindo a presença de um excesso de casos, ou ainda a presença de poucos casos. O primeiro, dificultaria o relacionamento entre informações coletadas nos casos, enquanto o segundo seria inviável considerando a realidade maioria das ferramentas estatísticas (RAGIN, 1987), que necessitam de uma amostra maior para garantir a confiabilidade do estudo.
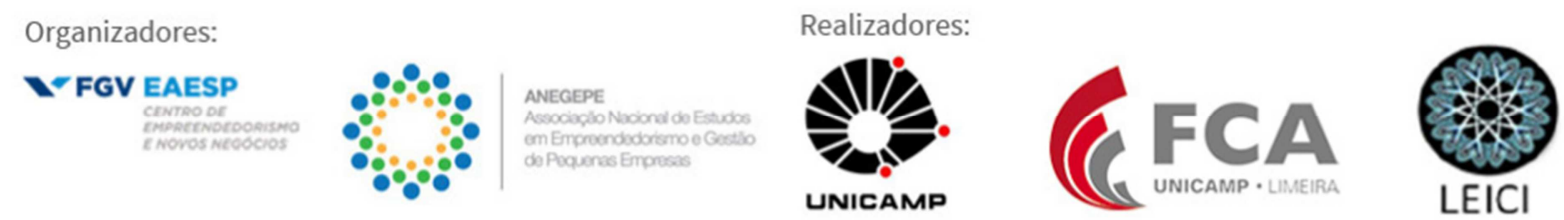
Assim sendo, o QCA fundamenta-se em análises de relações estruturadas e não de correlações, visto que teorias sociais, são normalmente formuladas verbalmente. Apresentando assim uma visão mais próxima da teoria, que a utilização de métodos quantitativos convencionais. As relações causais de necessidade e suficiência são indicadas a partir de um conjunto de relações existentes. De acordo com a necessidade, o resultado é consequência da condição causal. Com a suficiência, a consequência causal é um subconjunto do resultado (RAGIN, 1987).

O método QCA foi utilizado no modo Crisp-set, método clássico de análise de presença e ausência, que além de verificar a presença ou ausência da utilização das ferramentas, permite a análise do impacto destas com base na frequência de utilização. O processo de migração dos dados do questionário para os arquivos eletrônicos tomou como base a o software Excel para tratamento e posteriormente o software Tosmana, de acesso livre, para execução do QCA.

\section{Resultados e Discussão}

Esta etapa consiste na apresentação dos resultados e sua discussão com base no tratamento e análise dos dados realizados, além da utilização do software Tosmana para análise Crisp-set do método QCA. As primeiras três seções tratam de da discussão simples, considerando apenas uma das frentes que o estudo levanta, ferramentas, stakeholders ou resultados. Já as seções consecutivas apresentam o análise destes dados e a análise dos desempenhos.

\subsection{Perfil dos Respondentes}

Dos 14 respondentes, 11 são alunos da UnB campus Darcy Ribeiro, 1 da UnB FGA, 1 do UniCEUB e 1 da Universidade Católica de Brasília. A maioria se dá na UnB possivelmente pelo fato da primeira Empresa Júnior da região Centro-Oeste ter sido fundada na UnB há 25 anos atrás, servindo não apenas inspiração para o surgimento de outras Empresas Juniores, mas também como suporte a boas práticas de gestão.

Apenas 5 dos respondentes sãos membros de EJs que surgiram antes dos anos 2000, enquanto o restante fazem parte de EJs de nascimento mais recente. Isso que leva a crer que, a partir do momento que o Movimento Empresa passou a ser patrocinado com atividade de extensão pelas instituições de ensino, a criação e estruturação de outras EJs se tornou facilitada.

Acerca dos cursos de graduação dos quais os respondentes fazem parte, estes são variados, mas percebe-se uma predominância das engenharias, com 5 casos. Além disso, dentre os respondentes estão presentes os cursos de administração, design, economia, estatística, geofísica, nutrição, psicologia, relações internacionais. Sobre o semestre predominante, a maioria dos respondentes está entre o $5^{\circ}$ e $6^{\circ}$ semestre, contando com 7 casos. Isso leva a se considerar que é comum alunos ingressarem imediatamente no movimento assim que adentram a vida universitária e consequentemente atingem cargos superiores, como a presidência dentro de aproximadamente um ano e meio como membros.

Tratando da experiência destes com o Movimento Empresa júnior, dos 17 respondentes apenas dois possuíam cargos de vice-presidentes, enquanto os demais ocupam o cargo de presidente. Indicando que os altos cargos de gestão são os mais alinhados para responder sobre as ferramentas de gestão estratégia de uma Empresa Júnior. Mas assim, estes cargos podem ser alcançados na maioria das vezes em um período de 1 a 2 anos. Ao se considerar o tempo que estes membros estão nas EJs, conta-se com 4 casos que se encontram entre os intervalos de 13 a

Organizadores:

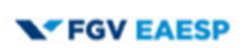

CrNTac Do
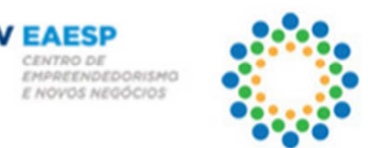

ANEGEPE Associaplo Nodiond do Estudios

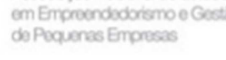
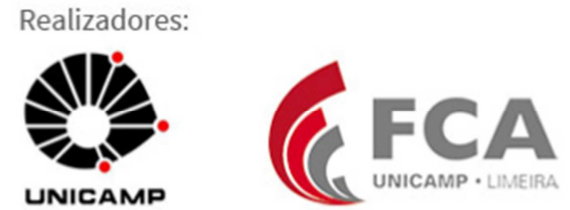

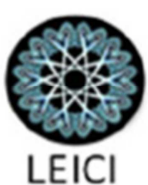


18 meses, outros 3 se encontram no intervalo de 19 a 24 meses. Ainda estão presentes, 4 casos no intervalo de 25 a 30 meses, 2 no intervalo de 31 a 16 meses e apenas 1 caso no intervalo 37 a 42 meses. Estes dados comprovam que a jornada de um empresário júnior até a presidência tem duração de 2 anos, cerca de metade ou dois quintos de sua graduação. E considerando o tempo de jornada e o semestre dos respondentes, é possível inferir que é comum alunos ingressarem no MEJ assim que adentram na universidade.

Estes têm idades que variam entre 19 e 25 anos, com 7 casos de respondentes com idades entre 21 e 22 anos, 6 casos entre 19 e 20 anos e 3 casos entre 23 e 25 anos. A experiência proporcionada pela experiência na Empresa Júnior permite alcançar um grau de maturidade suficiente para liderar uma organização com até mais de 50 membros com idade tão precoce. Reafirmando assim o momento de entrada dos membros no MEJ.

Por fim, no que se refere ao gênero, tem-se 10 homens nestes cargos de liderança e 4 mulheres. Pode-se inferir que esta maioria masculina acaba tendo relação ao peso da presença de Empresas Juniores nos cursos de engenharia, predominantemente preteridos por homens. Em contrapartida, percebe-se um movimento inclusivo, que é mais voltada para a meritocracia, uma vez que é comum nos depararmos com mulheres em outros cargos de gestão nas Empresas Juniores do Distrito Federal.

\subsection{Ferramentas de gestão utilizadas pelas Empresas Juniores}

Posteriormente, foi analisada a dicotomia entre o alto ou baixo grau de influência das ferramentas de gestão levantadas pelo estudo. As ferramentas analisadas foram: Orçamento (ORC), Benchmarking (BENCH), Planejamento Estratégico com análise de SWOT (PEeSWOT), Balanced Scorecard (BSC), Softwares (SOFT), CRM, Análise de Cenários (AC) e Análise de Stakeholders (AS). Os resultados estão presentes na Tabela 1.

Tabela 1 - EJs e suas ferramentas de gestão

\begin{tabular}{|c|c|c|c|c|c|c|c|c|}
\hline EJ & ORC & BENCH & PEeSWOT & BSC & SOFT & CRM & AC & AS \\
\hline EJ1 & 1 & 1 & 1 & 1 & 0 & 0 & 1 & 1 \\
\hline EJ2 & 1 & 0 & 1 & 1 & 1 & 0 & 1 & 0 \\
\hline EJ3 & 1 & 1 & 1 & 0 & 1 & 1 & 1 & 0 \\
\hline EJ4 & 1 & 1 & 1 & 1 & 1 & 1 & 1 & 1 \\
\hline EJ5 & 1 & 1 & 1 & 1 & 0 & 0 & 1 & 0 \\
\hline EJ6 & 1 & 1 & 1 & 0 & 1 & 0 & 1 & 1 \\
\hline EJ7 & 1 & 1 & 0 & 1 & 1 & 1 & 1 & 1 \\
\hline EJ8 & 0 & 1 & 1 & 1 & 1 & 0 & 0 & 1 \\
\hline EJ9 & 1 & 1 & 1 & 1 & 1 & 0 & 0 & 0 \\
\hline EJ10 & 1 & 1 & 0 & 0 & 1 & 0 & 0 & 0 \\
\hline EJ11 & 1 & 1 & 1 & 1 & 0 & 0 & 1 & 0 \\
\hline EJ12 & 1 & 1 & 1 & 0 & 1 & 1 & 0 & 1 \\
\hline EJ13 & 1 & 1 & 1 & 0 & 1 & 1 & 0 & 0 \\
\hline EJ14 & 1 & 1 & 1 & 0 & 0 & 0 & 0 & 1 \\
\hline Somatório & 13 & 13 & 12 & 8 & 10 & 5 & 8 & 7 \\
\hline
\end{tabular}

Fonte: Elaboração própria

Pode-se iniciar a análise dos resultados tratando sobre o as frequências de alto grau de influência das ferramentas Orçamento e Benchmarking em 13 dos 14 casos apresentados, representando 92\% da amostra. Para o Planejamento Estratégico somado à Análise de SWOT, encontra-se também um grande número de casos de alta influência, 12 dos 14 casos,
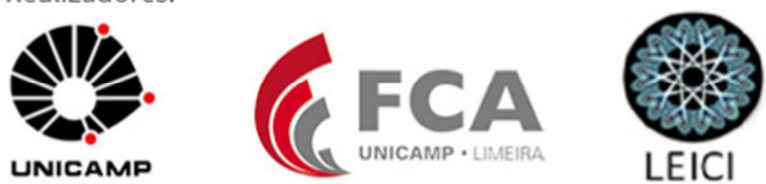
correspondendo a $86 \%$ dos casos. Em seguida vêm os Softwares, correspondendo à $71 \%$ dos casos. Empatados em quarto lugar estão o BSC e o Análise de Cenários, com 8 casos, correspondendo à $57 \%$ da amostra. Por fim, há apenas 7 casos de Análise de Stakeholders, representando 50\% e a Análise de Cenários, com 5 casos, correspondendo a 35\% da amostra.

Considerando esses dados, fica claro que as ferramentas de Orçamento e Benchmarking são intrínsecas às Empresas Juniores do Distrito Federal. A forte influência do Orçamento endossa a posição de Lunkes (2003, p.39) acerca da ferramenta, como onipresente no ciclo administrativo e como ferramenta de execução e controle das responsabilidades do planejamento e tomada de decisões. Evidenciando que as EJs estudadas, apesar serem organizações sem fins lucrativos, buscam manter sua saúde financeira, possibilitando investimento na capacitação de seus membros.

A alta frequência de casos de alta influência do Benchmaking também não é surpreendente, visto que o intercâmbio de conhecimentos de gestão e de mercado entre Empresas Juniores é incentivado não apenas pela federação do Distrito Federal (Concentro), mas também pela Confederação Brasileira de Empresas Juniores (Brasil Júnior). Este intercâmbio acaba se alinhando com a visão de Rigby (2009) sobre a ferramenta, como uma forma de buscar melhorar processos e práticas em geral, almejando a alavancagem dos resultados organizacionais.

O outro outlier a ser avaliado é o CRM, com a menor frequência. Considerando Rigby (2009) e Payne (2006), que apresentam como diferencial da ferramenta a grande quantidade de dados levantados sobre o grupo de clientes e os possíveis benefícios destes dados, pode-se dizer que tal benefício pode acabar gerando a inviabilização desta ferramenta para este tipo de organização. Tal frequência pode ser justificada pela dificuldade de gestão informacional por parte dos membros das Empresas Juniores, e até a ausência de um software específico para a utilização do marketing de relacionamento.

O questionamento a ser respondido posteriormente diz respeito ao análise das ferramentas de gestão e o desempenho organizacional, elencando assim quais são de alta influência que levam tanto à presença de um alto desempenho quanto a ausência desse, tendo como base as variáveis de desempenho elaboradas.

\subsection{Desempenho das Empresas Juniores}

Para finalizar as análises simples, esta seção trata do desempenho das Empresas Juniores. A Tabela 3 apresenta as frequências de presença de alto desempenho, ou ausência de alto desempenho. Lembrando que as duas primeiras métricas de resultado foram definidas como base nas medianas das divisões entre as médias de faturamento ou número de membros no intervalo dos últimos 3 anos (2014-2016). A última métrica toma como base o atingimento de duas mensurações, mediana do número média de membros e mediana do tempo médio de permanência dos membros, nesse mesmo intervalo. Assim para atingir o alto desempenho nessa métrica, as EJs deveriam cumprir ambos os pré-requisitos, ter no mínimo 44 membros e a manutenção destes por um intervalo mínimo de 13-18 meses.

Tabela 3 - Desempenhos das EJs

\begin{tabular}{|c|c|c|}
\hline EJ & Faturamento por Membro & Número de membros e Tempo Médio de Permanência \\
\hline EJ1 & 1 & 1 \\
\hline EJ2 & 1 & 1 \\
\hline EJ3 & 0 & 1 \\
\hline EJ4 & 1 & 1 \\
\hline EJ5 & 0 & 0 \\
\hline
\end{tabular}
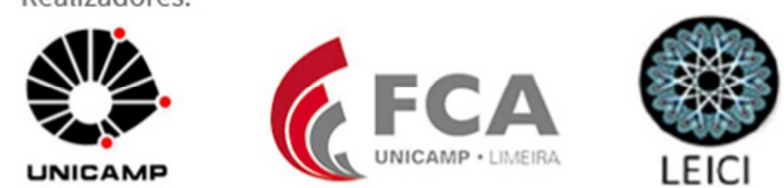


\begin{tabular}{|c|c|c|}
\hline EJ6 & 1 & 0 \\
\hline EJ7 & 1 & 1 \\
\hline EJ8 & 0 & 0 \\
\hline EJ9 & 0 & 0 \\
\hline EJ10 & 1 & 0 \\
\hline EJ11 & 1 & 1 \\
\hline EJ12 & 0 & 0 \\
\hline EJ13 & 0 & 0 \\
\hline EJ14 & 0 & 0 \\
\hline Somatório & 7 & 6 \\
\hline
\end{tabular}

Fonte: Elaborado própria

A discrepância entre os resultados das Empresas Juniores do Distrito Federal fica clara quando se analisa a frequência de resultados de alto desempenho nas variáveis de faturamento por membro, contando com apenas 7 casos $(50 \%)$ que faturam no mínimo R $\$ 641,75 /$ membro. A diversidade de possibilidades para esta variação de resultados, pode girar em torno das frentes mercadológica, dos modelos de prestação de serviços, da proposta do estudo, da presença ou ausência de ferramentas de gestão e da priorização de diferentes stakeholders.

Já no que diz respeito à variável de número de membros percebemos que as EJs brasilienses também apresentam dificuldade, com 6 casos (42\%) que atingem os pré-requisitos de no mínimo 44 membros e conseguem mantê-los por um período entre 13 e 18 meses. Estes números comprovam que a proposta do Movimento Empresa Júnior ainda se encontra em processo de consolidação e possui potencial de penetração nas universidades do Distrito Federal.

\subsection{Ferramentas de gestão vinculadas ao desempenho das Empresas Juniores}

Ao realizar o análise dos dados referentes às ferramentas utilizadas e aos desempenhos atingidos, com base no método QCA Crisp-set, o software TOSMANA permitiu extrair equações lógicas que demonstram as relações de necessidade e suficiência para o atingimento de determinado resultado. Trata-se em primeiro lugar da análise das ferramentas de gestão com presença e ausência de alto grau de influência com o desempenho das EJs.

\subsubsection{Desempenho das Empresas Juniores - Faturamento por Membro}

Inicialmente será feita a análise do faturamento por membro, retratando o atingimento ou não do alto desempenho nesta métrica. A primeira análise é sobre o desempenho 0, ausência de alto desempenho, e quais ferramentas conduziram a esse resultado. Posteriormente será analisado o desempenho 1.

Figura 1 - Análise das Ferramentas com Faturamento/Membro 1

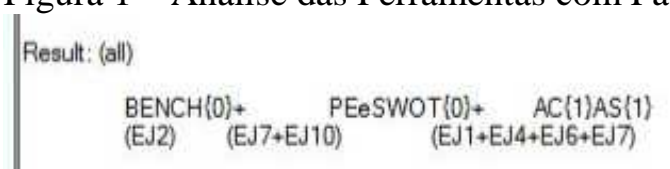

Fonte: Tosmana (2007)

Da mesma forma, para o desempenho 1 gerou uma equação, que é descrita da seguinte maneira: (1) ausência de Benchmarking, presente no caso EJ2; ou (2) ausência de Planejamento Estratégico, para os casos EJ7 e EJ10 ou (3) presença Análise de Cenários e Análise de Stakeholders, presente nos casos EJ1, EJ4, EJ6 e EJ7. Percebe-se que as ferramentas Benchmarking e Planejamento Estratégico com SWOT são suficientes, porém assim como Análise de Cenários e Análise de Stakeholders não podem ser caracterizados como necessários. Dito isso, é possível analisar as alternativas presentes na equação e assim realizar inferências.
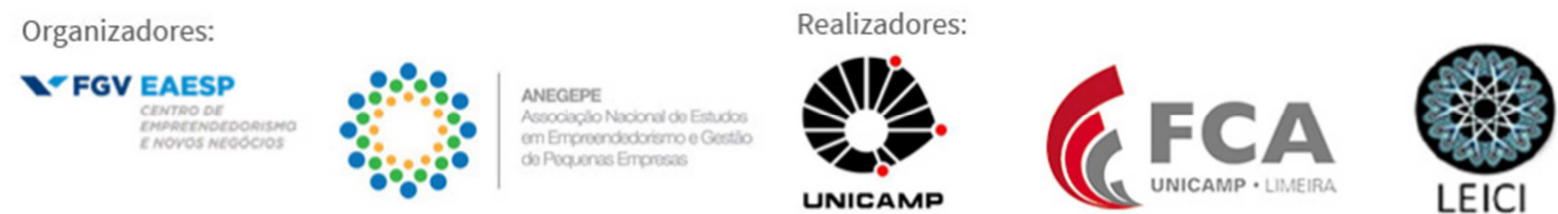
Para a alternativa (1) a ausência de alta influência do Benchmarking pode desencadear tal objetivo, uma vez que, apesar de Carlini e Vital (2004) afirmarem que a ferramenta auxilia nos processos de aprendizagem, não necessariamente esse processo desempenha papel fundamental considerando que as melhorias tanto processuais quanto de gerenciamento podem ser apenas um complemento para o desempenho da métrica em questão.

Já para a alternativa (2), a ausência do Planejamento Estratégico com SWOT, faz sentido, uma vez que a ferramenta, que pode apresentar uma dificuldade em sua gestão, permitiria o ajuste perfeito da cadeia sistêmica de decisões e a avaliação precisa de suas consequências (DEITSCHI, NASCIMENTO, 2008; RIGBY, 2009). Tal dificuldade poderia ganhar proporções maiores, considerando o alto grau de rotatividade característico do Movimento Empresa Júnior. Assim, se torna plausível, apesar de mais difícil, uma EJ atingindo alto desempenho nesta métrica de faturamentos por membro.

E para a alternativa (3) leva a tal desempenho considerando que, primeiramente a Análise de Cenários tem sua importância, uma vez que a ferramenta tem como propósito compreender e antever diferentes possibilidades futuras, visto que a tomada de decisão acaba por impactar diretamente o desenvolvimento profissional e acadêmico de seus membros (FURLAN, 2014). Adicionalmente, tem-se a presença da Análise de Stakeholders que permite o levantamento e gerenciamento de interesses para tomada de decisão mais embasada acerca daqueles que influenciam e são influenciados (FREEMAN, 1985, p.46) pelas atividades das Empresas Juniores.

4.4.2 Desempenho das Empresas Juniores - Número de Membros e Tempo Médio de

\section{Permanência}

Finalizando as análises sobre as ferramentas de gestão, será realizado a análise com a métrica de tempo médio e número de membros.

Figura 3 - Análise das Ferramentas com Membros e Tempo 1

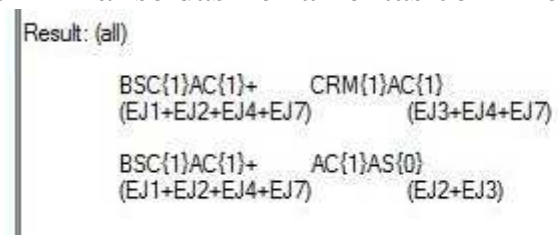

Fonte: Tosmana (2007)

Para o desempenho 1, foram geradas duas equações que são descritas da seguinte forma: (1) presença de BSC e Análise de Cenários, para os casos EJ1, EJ2, EJ4 e EJ7; ou presença de CRM com presença de Análise de Cenários. A alternativa (2) ainda pode ser alterada para (2.1) com a ausência de Análise de Stakeholders no lugar da presença de CRM. Pode-se dizer com base nas equações elaboradas que a ferramenta Análise de Cenário se mostra necessária para o atingimento desse desempenho, mas que nenhuma das ferramentas se apresenta suficiente. Com isso é possível realizar inferências sobre os motivos dessas ferramentas levarem a esse desempenho.

Sobre a alternativa (1) tem o BSC, em contraponto à análise anterior, colocando assim os membros sobre o enfoque da missão organizacional (KAPLAN, NORTON, 1997). Com isso, podem desencadear-se de iniciativas e objetivos estratégicos voltados para os seus membros. Além disso a alternativa conta com a presença da Análise de Cenários que busca de antever as possibilidades futuras, de cenários tanto internos quantos externos à organização, considerando o

Organizadores:

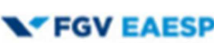

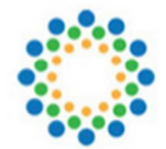

ANEGEPE

Associaplio Nowiond de Estudos

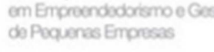
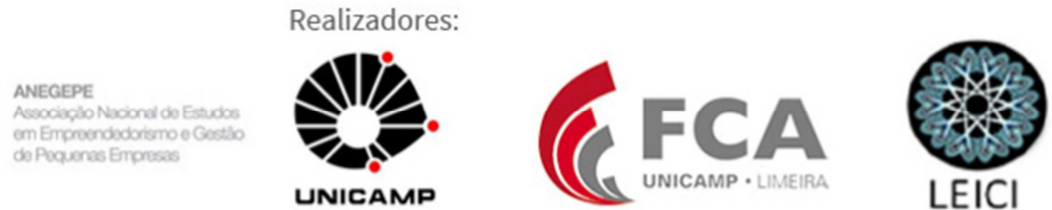
impacto da tomada das decisões organizacionais sobre a vida dos membros das Empresas Juniores. Ambas ferramentas que impactam diretamente para tal desempenho.

Já para a alternativa (2) da mesma forma ao tratar da Análise de Cenários, está agora somada à presença do CRM, que impacta indiretamente tal métrica, uma vez que um maior entendimento sobre os grupos de clientes e a elaboração estratégias (RIGBY, 2009), resultam em mais projetos vendidos, que como dito anteriormente, caracterizam a experiência Empresa Júnior e logo acabam por reter mais membros. Esta ainda pode ser adaptada para a ausência da Análise de Stakeholders, que apesar de no estudo de Ortega, Boaventura e Mascena (2016), desencadear um alto desempenho financeiro, pode ser que a presença de uma Análise de Cenários abrangente, seja suficiente para o atendimento das demandas destes stakeholders.

\section{Conclusões e Recomendações}

O Movimento Empresa Júnior ganhou destaque em função do crescimento constantes de faturamento frente ao faturamento dos projetos de consultoria realizados por todo o Brasil, com custo a baixo do mercado e favorecendo assim o micro e pequeno empreendedor brasileiro. Considerando que as Empresas Juniores atuam no mesmo formato que empresas de mercado, porém formadas apenas por alunos, é possível assim replicar o debate da discrepância entre desempenhos organizacionais.

Esse questionamento é trazido à tona por Rumelt, Schendel e Teece (1994), de como a heterogeneidade das organizações as leva a terem desempenhos diferentes. Hunger e Whellen (2002) complementam a discussão trazendo o impacto da utilização de ferramentas gestão no desempenho organizacional. E ainda a análise de stakeholders, aqueles afetados de alguma forma pelas ações de uma organização (FREEMAN et al., 2010), leva a questão a considerar tais aspectos que permitiram as organizações de modo geral alcançarem desempenhos diferenciados.

O presente estudo tem como o objetivo de determinar as relações existentes entre o desempenho organizacional das Empresas Juniores e, de um lado, as ferramentas utilizadas e, do outro, os stakeholders envolvidos nas tomadas de decisão.

Acerca das ferramentas de gestão, foi verificado que as mais utilizadas foram Orçamento e Benchmarking, com 13 casos. Acerca do Orçamento, indica respectivamente que conforme Lunkes (2003, p.39), a ferramenta, se apresenta como onipresente no ciclo administrativo para execução e no controle das responsabilidades do planejamento e tomada de decisões, demonstrando o esforço das Empresas Juniores brasilienses em manter sua saúde financeira. Da mesma forma o Benchmarking, incentivado pela Concentro, buscam melhorar processos e práticas em geral, almejando a alavancagem dos resultados organizacionais (RIGBY, 2009)

A respeito dos stakeholders priorizados, dentre os que utilizam a ferramenta de Análise de Cenários, os que foram priorizados por $100 \%$ das Empresas Juniores que utilizam a ferramenta, priorizam clientes, membros, ouras empresas, Concentro e ex-membros. Demonstrando assim que estes, de acordo com Freeman (1985, p.46) são aqueles que mais podem influenciar o desempenho organizacional.

Sobre o desempenho, foram elaboradas três variáveis de desempenho para Empresas Juniores, faturamento por membro e número de membros com o tempo de permanência destes. Assim os valores mínimos para caracterizar a presença de alto desempenho foram respectivamente, $\mathrm{R} \$ 641,75$ por membro e 44 membros com permanência de 13 a 18 meses. Foi identificado que apenas metade da amostra apresentou alto desempenho para projetos e
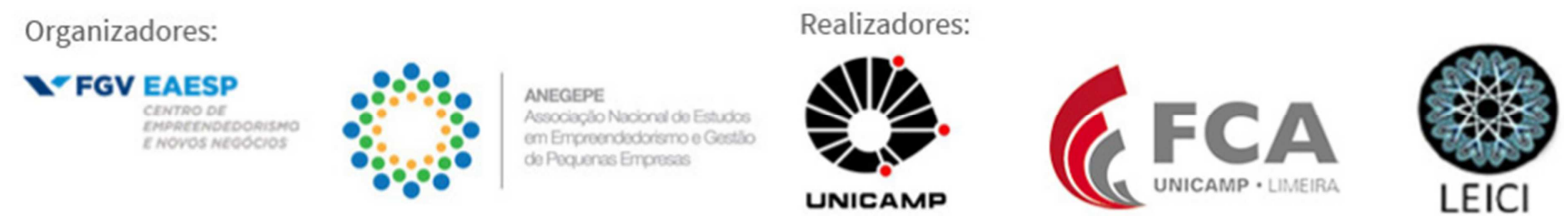
membros, que nos permite concluir que a variação de ferramentas e stakeholders está conectada a essa discrepância e para a variável de membros, e que a margem de penetração para o Movimento Empresa Júnior é grande, considerando a aderência dos alunos.

Com base nos cruzamentos entre as variáveis de desempenho e a utilização separada de ferramentas e de stakeholders, foi possível chegar à seis conclusões acerca do desempenho organizacional de sucesso para as Empresas Juniores dentro destas 3 métricas de desempenho levantadas.

Conclui-se que para a análise entre as ferramentas e o alto desempenho de faturamento por membro, a alternativa apresentada na equação que melhor retrata é a (3), que conta com presença de Análise de Cenários e Análise de Stakeholders. O primeiro tem sua importância em compreender e antever o futuro, e prever assim os possíveis desafios que as Empresas Juniores podem lidar em seus mercados (RIGBY, 2009). Enquanto o segundo permite o levantamento e gerenciamento de interesses daqueles que podem influenciar diretamente (FREEMAN, 1985, p.46) o faturamento por membro das EJs, tendo como base a realização de mais projetos, ou de projetos mais caros. Já acerca dos Stakeholders, percebe-se que as EJs que se destacaram nesta métrica acabaram por despriorizar stakeholders como professores orientadores, professionais de mercado, parceiros, outras EJs e até a Brasil Júnior. Porém a hipótese que se sustenta é que estas que adquiriram alto desempenho levam em consideração apenas aqueles influenciadores diretos para tal métrica.

Por fim, sobre a métrica de tempo e permanência dos membros com as ferramentas de gestão, tem-se duas alternativas dentre as equações apresentadas que melhor representam tal desempenho, a (1) e a (2). A alternativa (1) tem o BSC, colocando assim os membros como enfoque da missão organizacional (KAPLAN, NORTON, 1997), permitindo o desencadeamento de iniciativas e objetivos estratégicos voltados para os seus membros, somado à presença da Análise de Cenários que trata de antever as possibilidades futuras considerando o impacto da tomada das decisões organizacionais sobre o desenvolvimento dos membros das Empresas Juniores. A alternativa (2) acaba por trazer um impacto indireto ao trazer a presença da Análise de Cenários e CRM, uma vez que um maior entendimento sobre os grupos de clientes e a elaboração estratégias de vendas (RIGBY, 2009), resultam em mais projetos para as Empresas Juniores, que como dito anteriormente caracterizam a experiência Empresa Júnior e logo as levam a reter mais membros. E acerca os stakeholders para o alto desempenho da métrica, percebeu-se de modo geral que as EJs, que as que souberam despriorizar alguns stakeholders acabaram por se destacar nesta métrica. Assim sendo o diferencial propriamente não seria a priorização, mas o foco que estas EJs trazem para este stakeholders priorizados, reforçando a análise da ausência do alto desempenho da métrica rem que EJs que priorizaram um alto número de stakeholders acabaram tendo um desempenho inferior.

Assim sendo, considerando que este foi o primeiro trabalho acerca do desempenho das Empresas Juniores em função das ferramentas de gestão e stakeholders priorizados, conclui-se que a proposta foi atingida.

O estudo acabou por comprovar quais as ferramentas utilizadas pelas Empresas Juniores do Distrito Federal e a frequência de sua utilização, a presença de alto resultado nas métricas de faturamento por membro e número de membros / tempo de permanência, os stakeholders priorizados por estas nas suas tomadas de decisão e qual a relação entre ferramentas e stakeholders com os seus diferentes desempenhos.
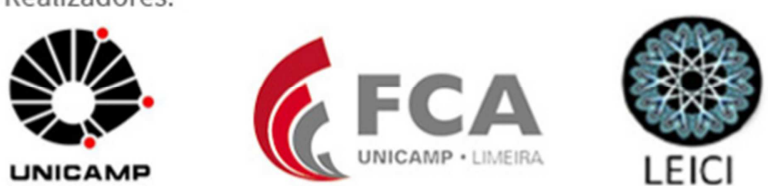
As relações entre ferramentas e alto desempenho acabam por servir para a gestão do conhecimento do Movimento Empresa Júnior e para o atingimento de boas práticas de gestão organizacional para todas as métricas utilizadas. Já para a Análise de Stakeholders, percebe-se que não ficou clara a relação entre priorização e desempenho e sim como a despriorização de pode levar a tal desempenho. Talvez essa não sejam uma boa abordagem para tratar o tema.

O estudo apresentou assim uma análise crítica sobre as ferramentas de gestão utilizadas e stakeholders priorizados por Empresas Juniores. Estes contribuem para a estruturação de uma gestão do conhecimento acadêmica e formal para este movimento crescente no Distrito Federal, Brasil e também outros países.

Percebeu-se como limitação do estudo o baixo número de casos para análise, em especial acerca das análises sobre stakeholders. Outro ponto foi a dificuldade de adquirir as informações de resultados organizacionais das Empresas Juniores, visto que cerca de $40 \%$ da amostra coletada foi filtrada pela ausência de alguma informação de resultado.

Como direcionamentos, para pesquisas futuras, fica a proposta de replicar o estudo em diferentes federações e até em diferentes países, visto a abrangência do Movimento Empresa Júnior. Sendo este um trabalho base de comparação entre práticas distintas utilizadas por diversos mercados regionais. Além disso, contar com um suporte maior das Federações para a coleta dessas informações de desempenho.

\section{Referências}

ACKOFF, R. L. Planejamento Empresarial. São Paulo: Atlas, 1980. 114p.

AFONSO, R. W.; ROMANO, M.; SILVA JÚNIOR, D. S.; PORTUGAL, G. T. Uma avaliação da adoção do BSC pelos Tribunais de Contas dos Estados. Cadernos Gestão Pública e Cidadania, v. 20, n. 66, p. 3-18, 2015.

BALM, G. J. Benchmarking um guia para o professional tornar-se - e continuar sendo - o melhor dos melhores. Rio de Janeiro: Qualitymark, 1995.

BANSAL, P. Evolving sustainably: a longitudinal study of corporate sustainable development. 2005

BRASIL JÚNIOR. Relatório Nacional Censo e Identidade 2014. Confederação Brasileira de Empresas Juniores .

CALEGARE, A. J. de A. Os mandamentos da qualidade total. 3. ed. Barueri: Inter-Qual International Quality Systems, 1999.

CLARKSON, M. B. E. A stakeholder framework for analyzing and evaluating corporate socialperformance. Academy of Management Review, New York: Jstor, v. 20, p. 92-117, jan. 1995.

COSTA, Suzana F. Ferramenta a serviço da inovação. Rumos. Rio de Janeiro, vol. 23, $\mathrm{n}^{\circ}$ 163, p. 22-23, Ago.1999

CRUZ, T. Sistemas de Informações Gerenciais: Tecnologias da Informação e a Empresa do Século XXI. 3 Ed. São Paulo: Atlas, 2003.

DIAS, C. N. A influência das redes interoganizacionais e da complementaridade de recursos no Desempenho da Inovação: Um Estudo comparativo Brasil-Espanha no setor de pesquisa agropecuária. Distrito Feral. 2015. 393 f. Tese (Doutorado em Administração) Programa de Pós-Graduação. Universidade de Brasília (UnB) Brasília, DF, 2015

(As demais referências estão ausentes devido a limitação de um máximo de 16 páginas)
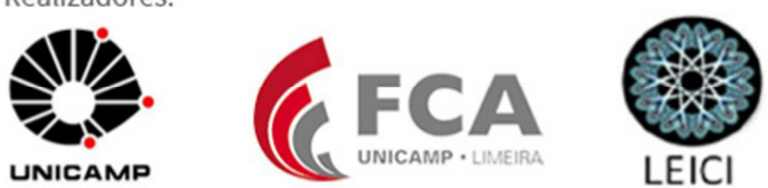